\title{
Modified Ribose Receptor Response in Isolated Diatom Frustules
}

CR Fairbanks

August 2011

Pacific Northwest

NATIONAL LABORATORY

Proudly Operated by Battelle Since 1965 


\title{
DISCLAIMER
}

This report was prepared as an account of work sponsored by an agency of the United States Government. Neither the United States Government nor any agency thereof, nor Battelle Memorial Institute, nor any of their employees, makes any warranty, express or implied, or assumes any legal liability or responsibility for the accuracy, completeness, or usefulness of any information, apparatus, product, or process disclosed, or represents that its use would not infringe privately owned rights. Reference herein to any specific commercial product, process, or service by trade name, trademark, manufacturer, or otherwise does not necessarily constitute or imply its endorsement, recommendation, or favoring by the United States Government or any agency thereof, or Battelle Memorial Institute. The views and opinions of authors expressed herein do not necessarily state or reflect those of the United States Government or any agency thereof.

\author{
PACIFIC NORTHWEST NATIONAL LABORATORY \\ operated by \\ BATTELLE \\ for the \\ UNITED STATES DEPARTMENT OF ENERGY \\ under Contract DE-AC05-76RL01830
}

Printed in the United States of America
Available to DOE and DOE contractors from the Office of Scientific and Technical Information,
P.O. Box 62, Oak Ridge, TN 37831-0062;
ph: (865) 576-8401
fax: $(865)$ 576-5728
email: reports@adonis.osti.gov

\begin{abstract}
Available to the public from the National Technical Information Service, U.S. Department of Commerce, 5285 Port Royal Rd., Springfield, VA 22161 ph: (800) 553-6847 fax: $(703) 605-6900$ email: orders@ntis.fedworld.gov online ordering: http://www.ntis.gov/ordering.htm
\end{abstract}

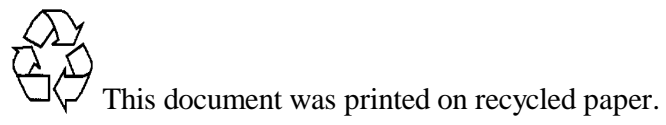




\section{Modified Ribose Receptor Response in Isolated Diatom Frustules}

CR Fairbanks

August 2011

Prepared for the U.S. Department of Energy under Contract DE-AC05-76RL01830

Pacific Northwest National Laboratory

Richland, Washington 99352 
Modified Ribose Receptor Response in Isolated Diatom Frustules

Carly Fairbanks

Office of Science, Science Undergraduate Laboratory Internship

\author{
Rochester Institute of Technology, Rochester, New York \\ Pacific Northwest National Laboratory - Marine Sciences Laboratory \\ Sequim, Washington
}

August 10th, 2011

Prepared in partial fulfillment of the requirement of the Office of Science, Department of Energy's Science Undergraduate Laboratory Internship under the direction of Guri Roesijadi and Kathryn Marshall of the Environment and Energy Directorate, Marine Biotechnologies group at Pacific Northwest National Lab 


\begin{abstract}
$\underline{\text { Abstract }}$
Diatoms are a distinctive group of microalgae with the unique ability to produce a highlyordered biosilica matix, known as the frustule. Diatoms hold significant potential in the biotechnology field as a silica scaffold for embedding proteins. In this study, we analyzed the funtionalization of biosilica with a receptor complex through genetic modification of the diatom, Thalassiosira pseudonana. Through the use of Förster Resonance Energy Transfer (FRET), the receptor was shown to remain active in transformed frustules after the inner cellullar contents were removed. In addition to protein functionality, growth condtions for T. pseudonana were optimized. Untransformed cultures receiving aeration grew more rapidly than stagnant untransformed cultures. Surprisingly, transformed cultures grew more quickly than untransformed cultures. This study demonstrates isolated diatom frustules provide an effective scaffold for embedded receptor complexes. Through this research, we provide the groundwork for the development of new biosensors for use in diagnostics and environmental remediation.
\end{abstract}

\title{
$\underline{\text { Introduction }}$
}

Over millions of years photosynthetic unicellular organisms, known as diatoms, have played an intergal role in aquatic ecosystems. Recently, diatoms have become a target for biosensor development due to their unique ability to produce a biosilica matrix, the frustules, on the outermost covering of the cell ${ }^{4}$. Each species produces a uniquely patterned silica frustule as a result of specific gene sequences for each species ${ }^{4}$. One particular species of diatom, Thalassiosira pseudonana (T. pseudonana), is one of two diatom species to have the genome fully sequenced ${ }^{1}$. At only 31.3 Mbp, T. pseudonana's short genomic sequence has made gene identification, i.e. frustule synthesis-related genes, easier to isolate making it a valuable model $\operatorname{organism}^{4}$.

Several studies have been conducted examining the intricacies and biology of the diatom frustule. In a study from the Scripps Institute of Oceanography, the components and mechanisms of the silica deposition vesicle in manufacturing embedded proteins in the frustule were examined ${ }^{3}$. The results of the research implicated several genes involved with the structural formation of the diatom frustule ${ }^{3}$. Another research team from the Georgia Institute of 
Technology identified the tpSil3 gene as a frustule-localizing gene and tagged the enzyme HabB with the tpSil3 sequence. From the investigation, the research team concluded that silicaembedded enzymes could be localized to the biosilica by tagging the enzymes with the tpSil3 sequence and still maintain functionality ${ }^{6}$. The results from both studies reinforce the potential that diatoms present for use in biosensor development.

The identification of proteins involved in frustule development has been particularly promising in biosensor development because using known diatom sequences involved in localizing proteins to the frustule, recombinant sensor proteins can be targeted to the biosilica through genetic manipulation of the diatom ${ }^{4}$. Current technologies developed to attach proteins to a silica matrix are often costly and can inactivate the protein due to harsh coupling conditions $^{6}$; however, the potential use of $T$. pseudonana provides an easy method to produce a large number of sensors with a desired receptor at one time under ambient conditions and at a relatively low cost

Although, there have been previous studies exploring the mechanisms of frustule development and the enzyme activity of embedded catalysts in living cells, our study specifically investigated the functionality of a complex Förster Resonance Energy Transfer (FRET)-based sensor in living cells as well as isolated diatom frustules. The main purpose of this paper is to demonstrate the capabilities of functionalizing diatom biosilica with a modified ribose receptor. In addition, we present information on the effects of various environmental conditions on the growth of cells in an effort to expand our understanding of diatom biology. For the purposes of the study a modified ribose receptor was used as a proof-of-concept, though other receptors could be developed in the future as the knowledge regarding diatoms biology expands. 
A previously prepared recombinant plasmid containing the genetic material for a ribose receptor flanked by the FRET fluorescent protein pair CyPet and YPet was used. As the ribose binds to the receptor, the protein under goes a conformational change resulting in a FRET response. FRET occurs as the FRET-receptor sensing protein is excited by cyan fluorescent light, which causes the cyan protein to emit a wavelength that excites the yellow protein if the two fluorescent proteins are close together. However, if the two proteins are further apart, in this case from the addition of the ribose, less yellow emission is produced. The ratio of the yellow emission to cyan emission, the FRET ratio, can then be compared over time to determine if a change in the ratio occurs. A decrease in the FRET ratio following ribose addition indicates proper receptor functionality. The development of this biosensor system could hold many applications to not only monitor the progress of a contamination clean up, but also in screening for impending pollution problems and possibly medically relevant diagnostic testing.

\section{Materials and Methods}

Growth Conditions of T. pseudonana. Wild type cultures of T. pseudonana (CCMP1335 strain) were grown in $\mathrm{F} / 2$ media with $100 \mu \mathrm{g} / \mathrm{ml}$ of penicillin and streptomycin at a relative $\mathrm{pH}$ of 8 at approximately $18-20^{\circ} \mathrm{C}$ under constant light, aeration, and stirring. The cultures were sparged weekly with $\mathrm{CO}_{2}$ to maintain physiologically relevant $\mathrm{pH}$. The transformed T. pseudonana strains were grown in the same conditions with the addition of nourseothricin as a selection agent for plasmid transformation. Shaking cell cultures were grown at $20^{\circ} \mathrm{C}$ with constant light on a shaker moving at $200 \mathrm{rpm}$. To monitor growth rates and culture viability, cells were counted using a glass slide hemocytomer. 
Tranformation of Diatom Cells. The modified ribose receptor expressing diatoms cells were transformed with the previously constructed vector pTpfcp-Sil3-CyPet-RBP-Ypet:fcp-nat (Fig. 1). The diatoms cells were transformed with high-pressure helium bombardment (Bio-Rad, Inc.) and selected for nourseothricin-resistance and cyan and yellow fluorescence.

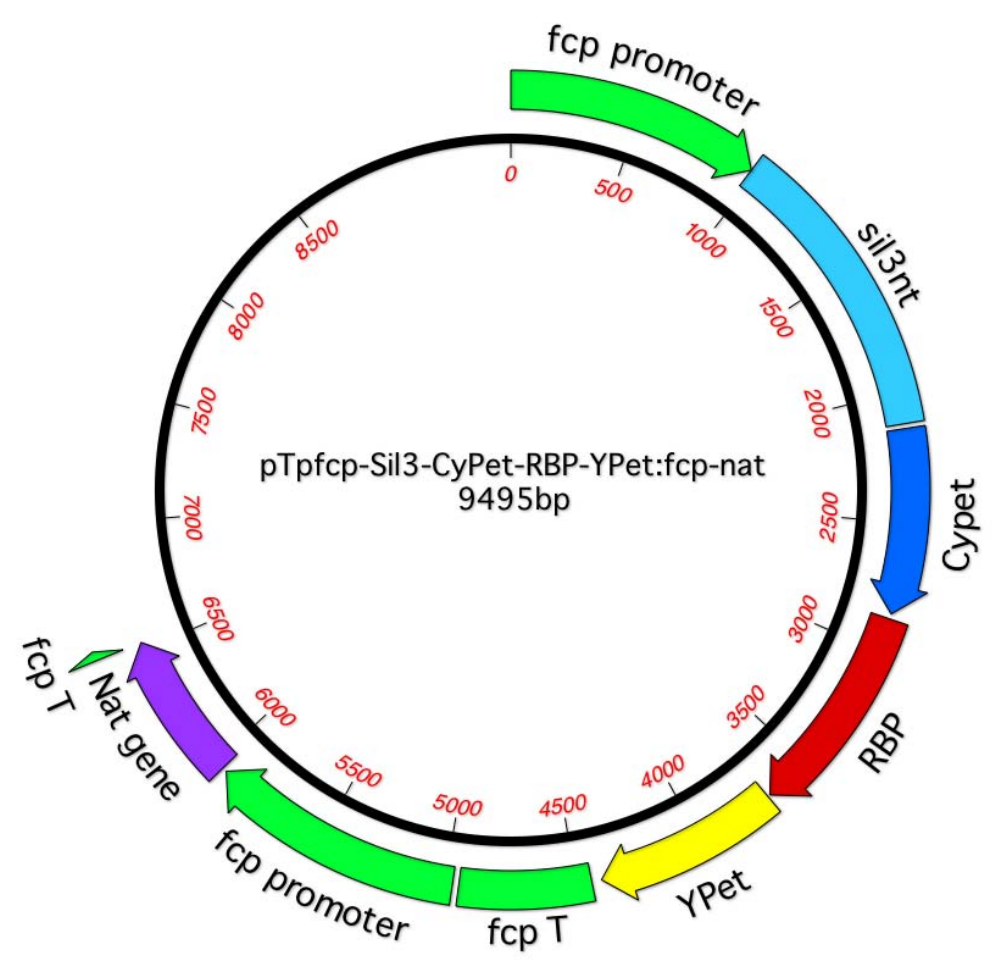

Fig. 1. Vector map of $p$ Tpfcp-Sil3-CyPet-RBP-YPet:fcp-nat. The plasmid contains both the CyPet-RBP-YPet (CRY) expression cassette tagged with Sil3 on the N-terminus of the expression cassette and the Nat gene coding for nourseothricin-resistance.

Frustule Isolation. The isolation procedure was modified from the frustule isolation protocol outlined in Poulsen et al., $2007^{5}$. Approximately $1 \times 10^{6}$ cells were sonicated (Fisher Scientific Model 500 Sonic Dismembrator) with an amplitude of 10\% for a duration of 5 x $30 \mathrm{sec}$ on/off. 
The sonicated culture was centrifuged at $0.8 \mathrm{rpms}$ for 5-10 min in a microcentrifuge. Cells spun at greater rates produced questionable FRET results.

Förster Resonance Energy Transfer (FRET) Analysis. One hundred microliters of isolated frustules were adhered to $35 \mathrm{~mm}$ collagen-coated Petri dishes (MatTek) for $30 \mathrm{~min}$. Plates were washed with $100 \mu \mathrm{l}$ of DI water to remove debris and non-adhered frustules. This was repeated until all non-adhered frustules were removed. The isolated frustules were then exposed to fluorescent cyan light for $5 \mathrm{~min}$ to photobleach the viewing area. Using Metamorph software (Molecular Devices Inc.), dual fluorescent images were simultaneously recorded every minute for up to $20 \mathrm{~min}$ by exciting frustules with the cyan wavelength of $430 \mathrm{~nm}$ and reading the emission fluorescence in both cyan $(485 \mathrm{~nm})$ and yellow $(530 \mathrm{~nm})$. Five seconds prior to each image acquisition the shutter was manually opened, and following picture acquisition the shutter was closed. At the midpoint of the time lapse, $300 \mathrm{mM}$ ribose was added to the Petri dish. The yellow relative fluorescent units (RFU):cyan RFU ratio was compared over time to determine a FRET response. The background for each wavelength was subtracted to account for the increase in RFU upon ribose addition. The procedure was repeated for both untransformed and transformed frustules.

Cryopreservation. Approximately $1.5 \times 10^{6}$ cells were spun down and resuspended in a $12 \%$ DMSO-F/2 media solution. The cell suspension was transferred to cryopreservation vials and sealed with heat shrink-wrap tubing. The tubes were then frozen at a rate of $-1^{\circ} \mathrm{C} / \mathrm{min}$ to $-80^{\circ} \mathrm{C}$ using a Nalgene Mr. Frosty (Thermo Scientific). Vials containing the cells were moved to liquid nitrogen. 
To bring cryopreserved cells to room temperature, vials were taken out of liquid nitrogen and step-wise warmed by leaving them for $24 \mathrm{~h}$ in a Mr. Frosty cooled to $-20^{\circ} \mathrm{C}$ then left on the counter top at room temperature until the frozen cell solution had thawed. The liquid cell solution was then spun down and resuspended in $\mathrm{F} / 2$ media with $100 \mu \mathrm{g} / \mathrm{ml}$ of penicillin and streptomycin. The resuspended cultures were then left in the shaking incubator. Various concentrations of DMSO ranging from $8 \%$ to $25 \%$ were also tested but results were inconclusive.

\section{$\underline{\text { Results }}$}

Fluorescence Expression In Naturally Occurring and Isolated Frustules. We noticed in living transformed cell cultures that there were consistently what appeared to be circular hollow shaped objects. We examined these structures with fluorescence microscopy to determine if they were living diatoms. By using the red auto-fluorescence of the chloroplasts, we could determine if the circular objects were living cells (Fig. 2). Upon inspection, no red fluorescent chloroplasts were seen, but both yellow and cyan fluorescence was present. The circular objects were proposed to be naturally occurring frustules, in which the cell died and the cellular material was degraded leaving the frustule. 


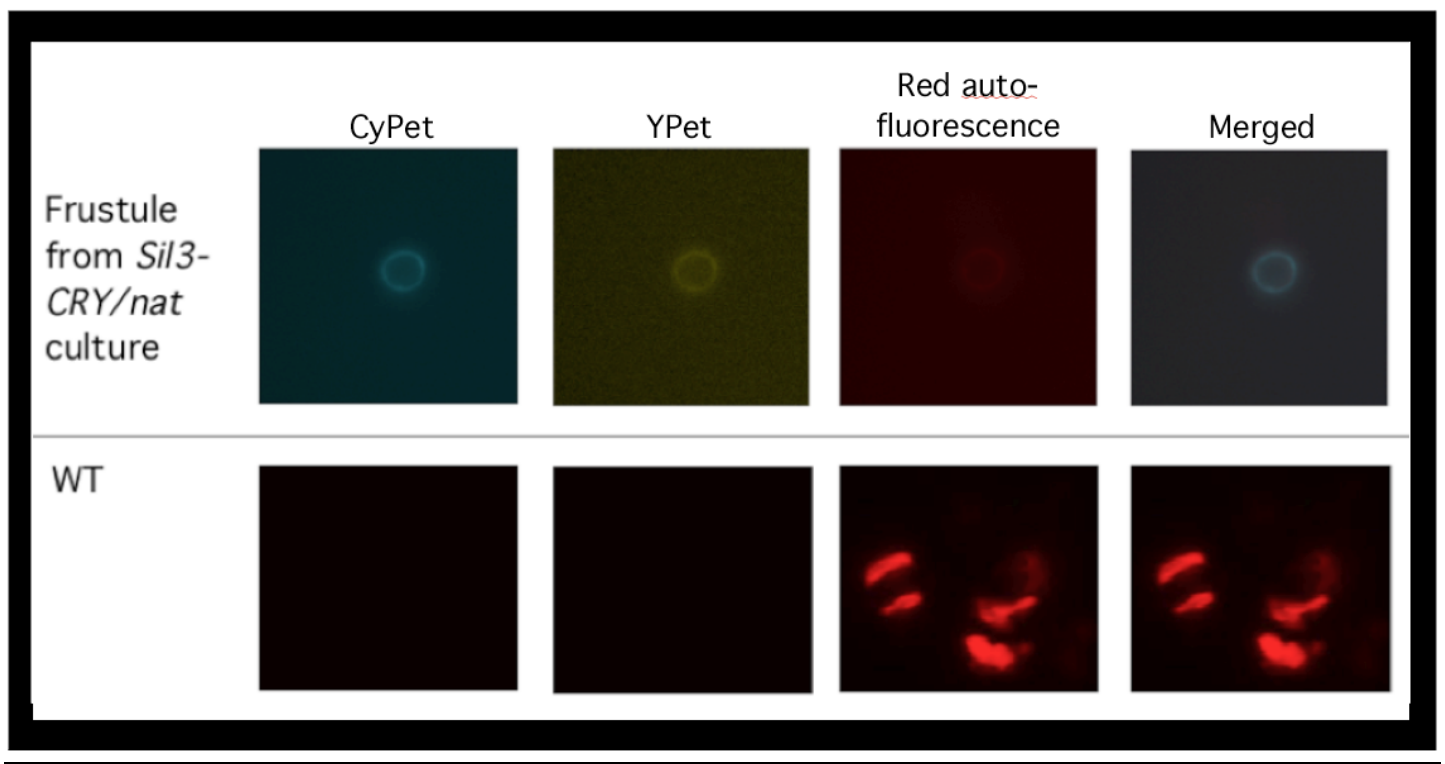

Fig. 2. Fluorescence in Naturally Occurring Frustules. The presumed frustules were examined by fluorescence microscopy to determine the expression profile of yellow and cyan fluorescence. Red auto-fluorescence was used as an indicator of living cells containing chloroplasts. WT cells displayed the red auto-fluorescence but no cyan or yellow fluorescence.

FRET Results of Naturally Occurring Frustules. To examine the FRET response in naturally occurring frustules, frustules were chosen out of live cell cultures using microscopy and subjected to time lapse imaging over the course of $10 \mathrm{~min}$. Naturally occurring frustules produced a FRET decrease of $26.2 \%$ (Fig. 3). This response was outside the $95 \%$ confidence interval compared to the average $8.3 \%$ FRET response in untransformed, wild type (WT) frustules.

Optimization of Isolated Frustule Protocol. In order to examine the functionality of the ribose receptor in a high number of transformed (TR) frustules, a protocol for frustule isolation was 
optimized. The initial protocol tested was based upon a protocol developed by Friger et al., 2006 utilizing a sodium dodecyl sulfate (SDS) and ethylenediaminetetraacetic acid (EDTA) centrifugation treatment ${ }^{3}$. Following this protocol, frustules were isolated in large numbers; however, when tested for FRET response, the frustules did not produce any commonly patterned results (data not shown). It was noted in Poulsen et al., 2007 that an SDS treatment had inactivated their biosilica-embedded enzyme. To compensate, the team used an EDTA/sodium phosphate buffer solution and a detergent mixture of octylphenyl-polyethylene glycol (Igepal CA-630)/sodium sulfate to centrifuge and sonicate the cells. We modified this protocol to include Tween-20 as a chemically indistiguishable replacement for Igepal CA-630. Following this modified protocol, frustules were isolated and tested for FRET but still produced an inconsistant FRET response (data not shown). It was noted by a collegue working with living TR diatoms that centrifuging cells resulted in a decrease in receptor response. To bypass the issue, a method was developed in which the live cells were sonicated to remove the cellular materials and centrifuged at very low rpms to minimize centrifugation stress on the biosilica. Frustules isolated from the optimized protocol displayed an average decrease in FRET response of 19.7\% that was significantly higher than the average $8.3 \%$ FRET response in WT isolated frustules ( $p$ value <0.05; Fig. 4). 


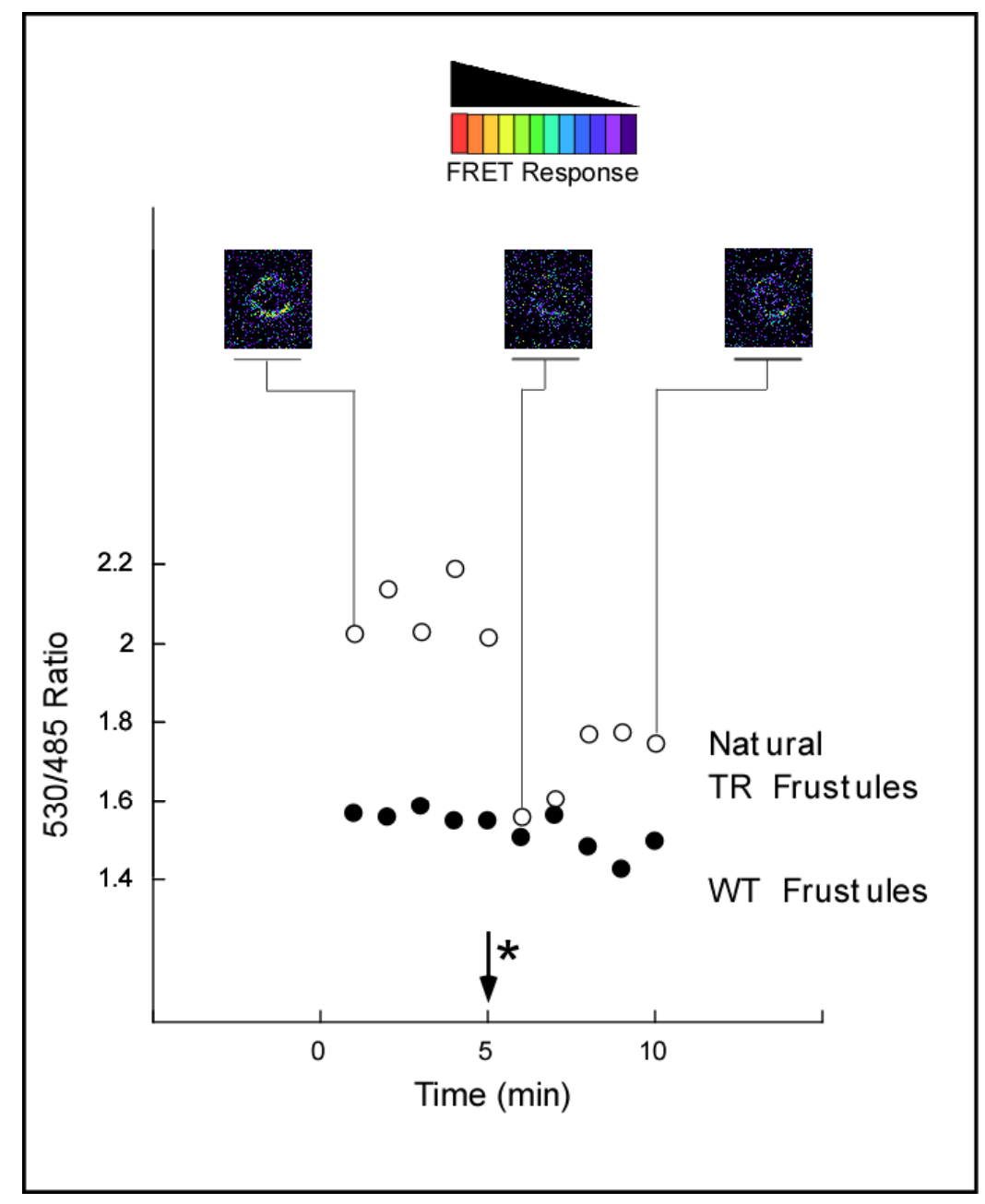

Fig. 3. FRET Results in Naturally Occurring Frustules. The naturally occurring transformed (TR) frustules were chosen out of live cell cultures using microscopy and subjected to time lapse imaging over the course of $10 \mathrm{~min}$. Samples were exposed to cyan fluorescence (430 $\mathrm{nm})$ every min and simultaneously captured emission relative fluorescent units (RFU) at the cyan emission $(485 \mathrm{~nm})$ and yellow emission $(530 \mathrm{~nm})$. Ribose was added after an initial 5 min sampling $(*)$. The yellow:cyan RFU ratio is reported as the FRET response comparing TR to WT frustules. TR frustule images are pseudocolored to reflect changes in FRET with red pseudocoloring representing high FRET response and purple or black pseudocoloring representing low FRET response. 
Comparative Growth Conditions of TR and WT Cultures. To determine if cell transformation affected the growth rate of diatoms, WT and TR cell cultures were inoculated with approximately $0.5 \times 10^{6}$ cells in $\mathrm{f} / 2$ media and allowed to grow for $8 \mathrm{~d}$ in a shaking incubator under constant light. Cell counts were taken every $24 \mathrm{~h}$ for the course of $8 \mathrm{~d}$ (Fig. 5). Overall, TR cells grew more quickly than WT cells over the time course. TR cells reached a maximum approximate cell density of 1,362,500 cells/ml after 139 hours. In comparison, the highest cell density reached by WT cells at $139 \mathrm{~h}$ was $537,500 \mathrm{cells} / \mathrm{ml}$. This was the highest overall cell density achieved by WT cells. It was noted the WT cells repeatedly tended to clump, while the transformed cells regularly remained suspended in the media. This may be contributed to various factors including changes in surface protein profiles due to targeting recombinant proteins to the biosilica, or the loss of signaling/receiving signals from other cells that would typically signal to aggregate.

The effect of aeration on cell growth was also investigated by setting up two WT cultures under separate conditions. The first culture received constant aeration while the second remained stagnant. As expected, the culture receiving aeration had a higher cell density than the stagnant culture over the course of the $8 \mathrm{~d}$ study. The culture grown with constant aeration reached the highest concentration of $1,370,000$ cells/ml after 129.8 hours, but the culture grown in stagnant media peaked at 682,500 cells/ml after 19 hours (Fig. 6). 


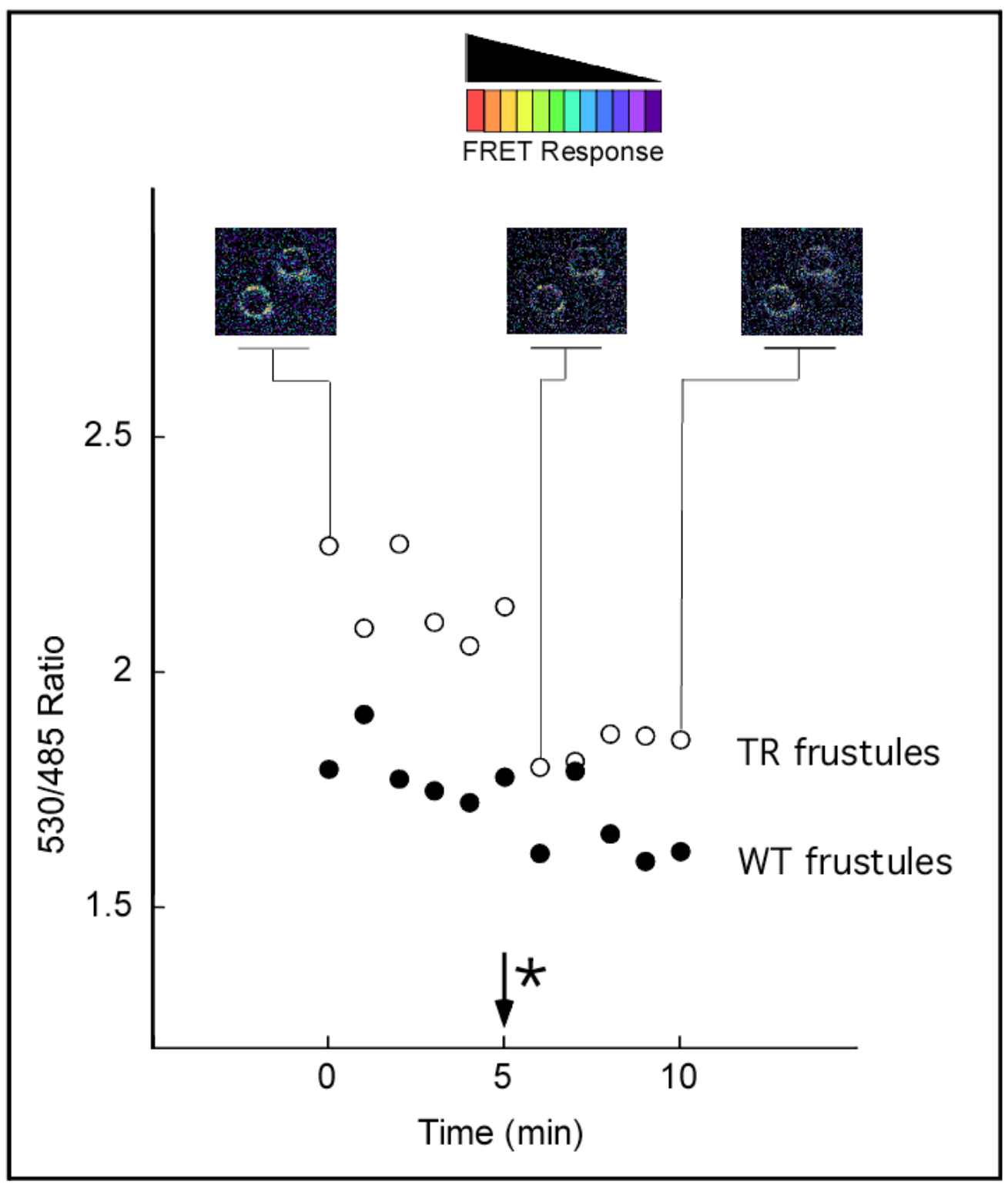

Fig. 4. FRET Results in Isolated Frustules. The isolated TR frustules were purified and subjected to time lapse imaging over the course of 10 min as stated in Fig. 3 legend. The 530/485 ratio is presented as an indicator of FRET response. TR frustule images are pseudocolored to reflect changes in FRET with red pseudocoloring representing high FRET response and purple or black pseudocoloring representing low FRET response. 


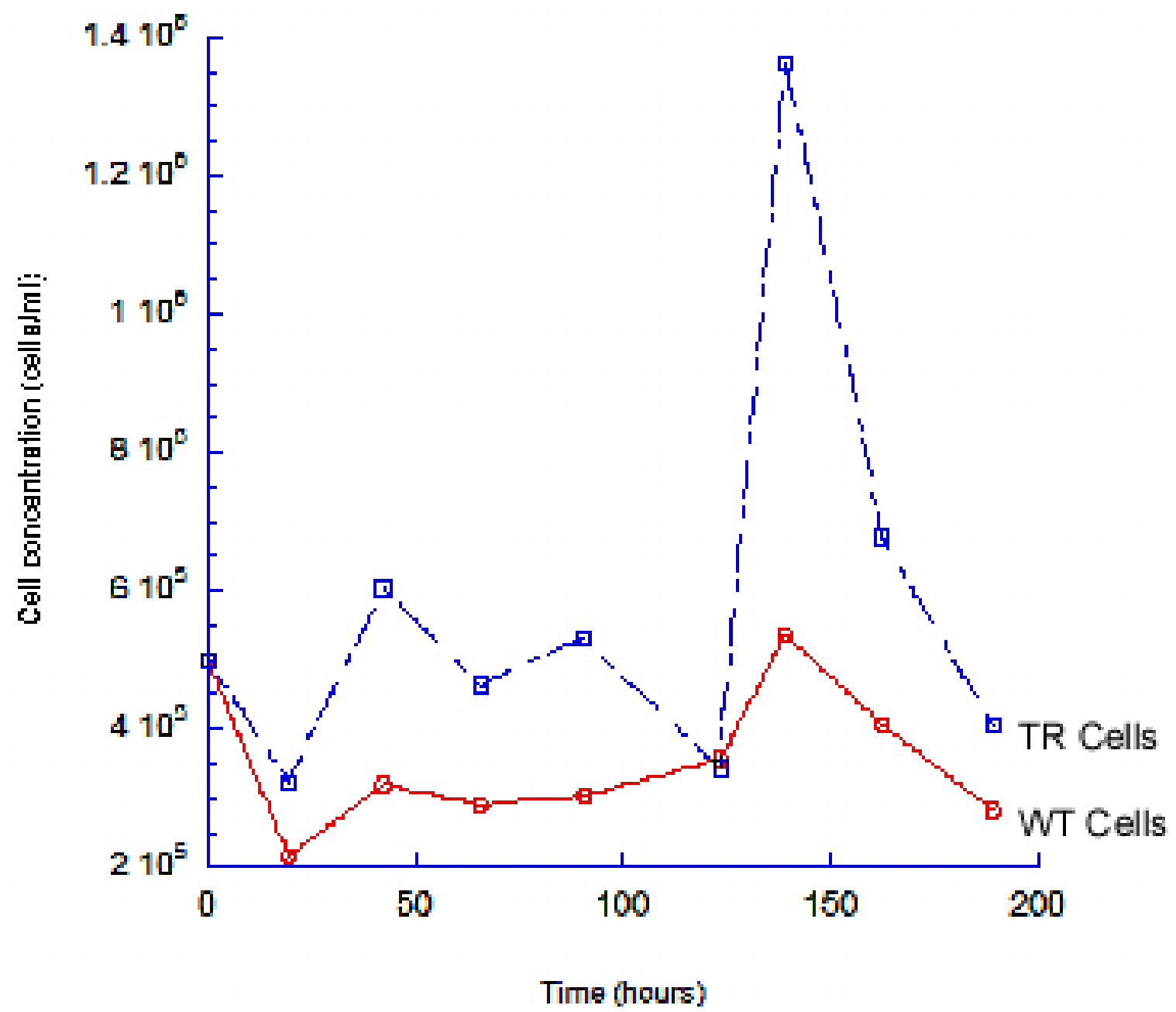

Fig. 5. TR Cells Grow to a Higher Cell Density than WT Cells. To determine the effect of transformation on cell growth, WT and TR cultures were seeded at a density of $0.5 \times 10^{6}$ cells/ml. Cell concentrations of WT and TR cell cultures were compared over the course of 8 days with cell counts taken at approximately every $24 \mathrm{~h}$. 


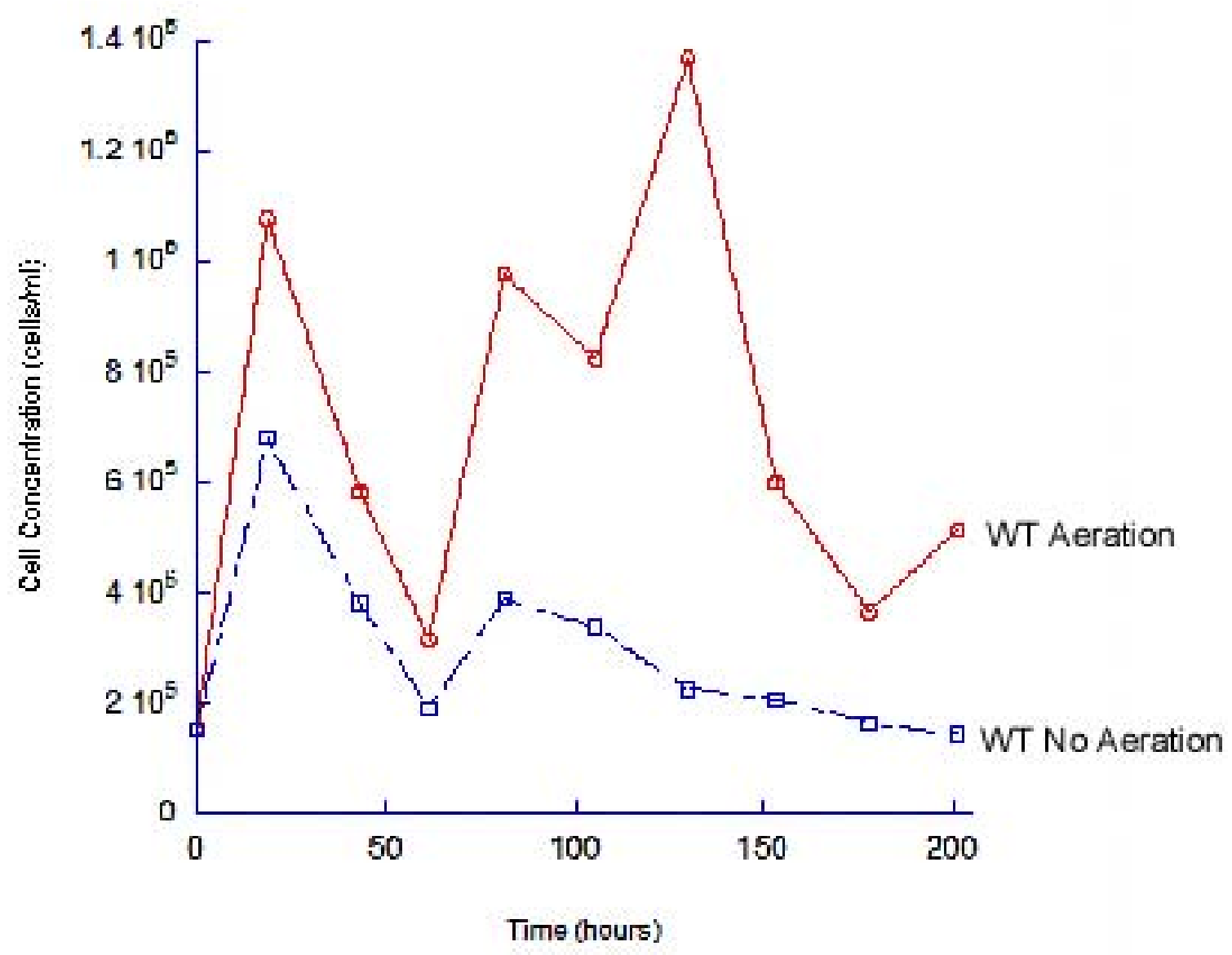

Fig. 6. Aeration Improves WT Cell Growth. The cell densities of aerated and stagnant WT cell cultures were monitored. Each culture was seeded at a density of 150,700 cells/ml in F/2 media. Cell counts were recorded every 24 hours for 8 days.

Cryopreservation of Diatom Cells. A protocol for the cryopreservation of diatom cells was optimized in order to maintain samples for future use. Different DMSO concentrations were tested between $8 \%-25 \%$ in $\mathrm{f} / 2$ media. A DMSO concentration of $12 \%$ was observed to produce 
the highest number of viable cells after bringing the cells out of cryopreservation based on microscopic observation of chloroplast auto-fluorescence. It was noted that there was white particulate matter suspended in the thawed cell cultures suggesting an initial cell die-off after the cells were brought out of cryopreservation. This suggests that using a 12\% DMSO-F/2 solution to cryopreserve diatoms is an effective means to store cultures over time for cell line retention.

\section{$\underline{\text { Discussion }}$}

The main objective of this study was to examine the functionality of the ribose receptor in a biosilica-embedded/cell-free system. Initial efforts utilized protocols that included a large amount of centrifugation but produced questionable FRET results. In contrast, naturally occurring frustules that underwent no centrifugation demonstrated a consistent FRET response indicating the receptor is capable of functioning even after the cell dies. This might suggest that centrifugation stress denatures or damages the receptor/frustule system. Therefore, the use of a protocol primarily based on sonication to get rid of the cellular material with very limited centrifugation bypassed many of the issues seen earlier in the protocol optimization process.

A previous study examining diatoms transformed with the enzyme HabB have also found that functionality was compromised by certain isolation methods (Poulsen et al., 2007). Poulsen et al. found that the use of SDS and acetone used in their original isolation protocol inhibited HabB enzyme activity ${ }^{6}$. Because of this, they optimized their protocol to include Igepal and sonication instead of stringent organic chemicals. Optimizing a frustule isolation protocol that occurs under ambient temperature and $\mathrm{pH}$ conditions is beneficial not only for cost-effectiveness, but also to circumvent some of the denaturing issues other protocols have experienced while trying to immobilize proteins in a silica matrix ${ }^{6}$. 
The isolation of functional transformed frustules could prove to be valuable in biosensor applications as a silica matrix without the need to keep cell cultures alive. In addition, the activity of an enzyme incased in the frustule after long-term storage has been investigated to determine if liquid nitrogen storage affects the overall usage of transformed biosilica. Poulsen et al., 2007 investigated long-term storage of transformed cell lines containing the HabB enzyme and found that the enzyme maintained over $80 \%$ of its functionality ${ }^{6}$. Although enzymes and receptors differ from protein to protein, the fact that silica-embedded enzymes maintained such a high level of activity after storage provides promise for use of this technology in downstream applications. Knowing this, a large quantity of transformed cell lines with any number of biosensors can be established, cryopreserved, and housed in a small facility at a relatively low cost without the need to maintain each individual cell line culture.

Following analysis of growth conditions, aeration was determined to play an important role in diatom growth. The cultures that received aeration grew to a cell density almost twice as large as the culture that did not receive any aeration. This suggests the aeration provides necessary uniform gas and nutrient levels throughout the culture for diatoms to grow, develop, and divide to reach a higher density more quickly than cultures grown without aeration. However, the use of stagnant media was concluded to be a useful tool to slow culture growth and maintain cultures at lower concentrations. This is beneficial if there is a need to keep large volumes of culture but not actively grow them.

Unexpectedly, the TR cells grew to a higher cell density compared to WT cells. It was noticed that the WT cells tended to clump after a period of shaking and collected at the bottom of a culture tube, while TR cells primarily remain in suspension. The difference in growth patterns 
may be due to a variety of factors including the possibly that by transforming the diatom cells with a biosilica-targeted protein complex, other biosilica-embedded protein signatures are disrupted causing the cells to be less likely to adhere to each other. However, it still remains unknown why exactly the WT diatoms tended to clump more than the TR cells, or why TR cells grew faster than WT cells.

This study provides support for a diatom-based biosensor system using a modified ribose receptor immobilized in biosilica as proof-of-concept. The results also offer methods to maintain transformed diatom cells, as well as isolate and analyze receptor function in frustules. Tests regarding dose response, receptors for other chemicals, and commercial storage information could be objectives for future studies. Future research endeavors could also explore using environmentally and medically-relevant receptor proteins in place of the ribose receptor. Through the continuation of diatom biosensor research, new tools could be established to monitor finite amount of an exogenous material such as Trinitrotoluene (TNT) or other pollutants in the environment. Developing the tools of tomorrow with the research of today can protect and preserve the environment not only during our generation but for future generations as well.

\section{Acknowledgements}

This study was partially funded by the Marine Sciences Lab at Pacific Northwest National Laboratory, U.S. Department of Energy, Office of Science, through the Science Undergraduate Laboratory Internship program. I would like to thank my mentors Dr. Guri Roesijadi and Dr. Kathryn Marshall, as well as my fellow SULI student Hanna Miller for all of 
their help and encouragement. Also, many thanks to PNNL and the SULI program for their generous support.

\section{Works Cited}

1. Armbrust, E. V. (2004). The Genome of the Diatom Thalassiosira Pseudonana: Ecology, Evolution, and Metabolism. Science, 79-86.

2. Bozarth, A., Maier, U.-G., \& Zauner, S. (2009). Diatoms in Biotechnology: Modern Tools and Applications . Applied Microbial Biotechnology, 195-201.

3. Friger, L. G., Radabaugh, T. R., Haynes, P. A., \& Hildebrand, M. (2006). Identification of Protein from a Cell Wall Fraction of the Diatom Thalassiosira pseudonana. Molecular \& Proteomics , 182-193.

4. Kroger, N., \& Poulsen, N. (2008). Diatoms-From Cell Wall Biogenesis to Nanotechnology. Annual Review of Genetics , 83-107.

5. Lager, I., Fehr, M., Frommer, W. B., \& Lalonde, S. (2003). Development of a Fluorescent Nanosensor for Ribose . Federation of European Biochemical Societies , 8589.

6. Poulsen, N., Berne, C., Spain, J., \& Kroger, N. (2007). Silica Immobilization of an Enzyme through Genetic Engineering of the Diatom Thalassiosira pseudonana . Angewandte Chemie , 1843-1846. 


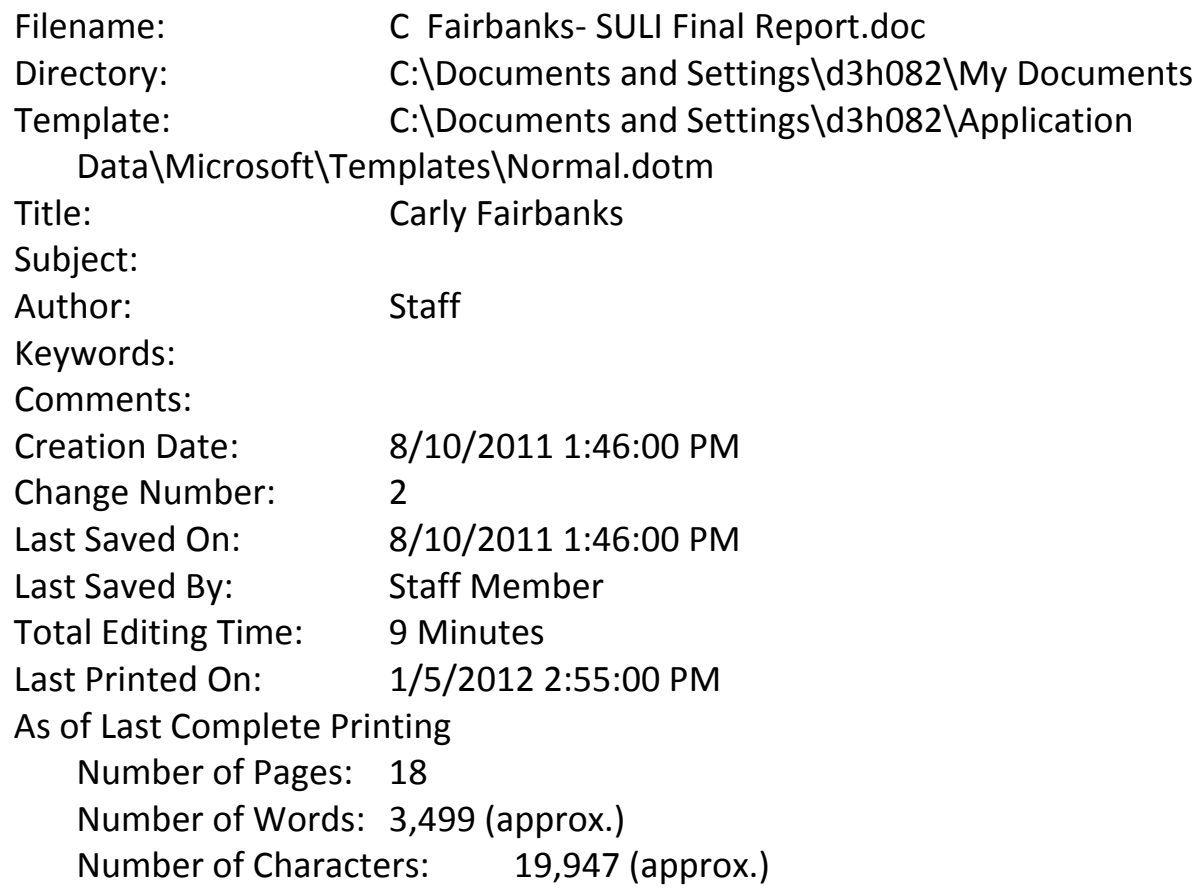

